\title{
EFMI Working and Project Groups - Overview and Current Activities
}

\author{
Alexander Hörbst ${ }^{1}$, Anne Moen ${ }^{2}$, Patrick Weber ${ }^{3}$ \\ 1 EFMI Press and Information Officer, UMIT - Private University for Health Sciences, Medical \\ Informatics and Technology, Austria \\ 2 EFMI Vice-President, University of Oslo, Norway, Institute for Health and Society, Faculty of Medicine \\ 3 EFMI President, Nice Computing, Le Mont-sur-Lausanne, Switzerland
}

\section{Current Working and Project Groups}

EFMI is a nonprofit organisation concerned with the theory and practice of Information Science and Technology within Health and Health Science in a European context. Apart from other activities EFMI's success heavily relies on the work been done by its working and project groups. Currently EFMI has 18 active working and project groups:

- CLIOMICS - Clinical ..omics

- EDU - Education in Health Informatics

- EHR - Electronic Health Records

- EVAL - Assessment of Health Information Systems

- HIIC - Health Informatics for Interregional Cooperation

- HIME - Health Information Management Europe

- HOFMI - Human and Organisational Factors of Medical Informatics

- IDeS - Information and Decision Support in Biomedicine and Health Care

- IDR - Informatics for the Disabled and Rehabilitation

- LIFOSS -Libre/Free and Open Source Software in Health Informatics

- MCRO/MBDS - Casemix, Resources Management and Outcomes of Care

- MIP - Medical Image Processing

- NLU - Natural Language Understanding

- NURSIE - Nursing Informatics in Europe

- PCI - Primary Care Informatics

- PPD Personal Portable Devices

- SSE - Safety, Security and Ethics

- TRACE - Traceability of Supply Chains

The following paragraphs provide detailed information about selected working and project groups.

\section{EFMI WG EDU}

Education in Health Informatics

\section{Chair:}

John Mantas

Health Informatics Laboratory

University of Athens, Greece

E-mail:.jmantas@nurs.voa.gr

Co-Chair:

Arie Hasman

Department of Medical Informatics

University of Amsterdam, The Netherlands

E-mail:a.hasman@amc.uva.nl

http://en.hil.nurs.uoa.gr/wgedu.html

\section{Main Objectives:}

The introduction of eHealth applications as well as of the Biomedical and Health Informatics (BMHI) discipline into the health care domain requires high quality educated and trained health care professionals in the field. Education is considered as the most appropriate tool to improve greatly the acceptance attitudes and behavior of the professionals working in the healthcare environment towards eHealth applications. EFMI is well aware of the importance of Education and in its history the working group in education was the first working group to be established. Since education has an international value and there no borders in its objectives, the working group seeks to achieve International cooperation in its main objectives which they may be summarized as follows: information on existing programs and curricula in the field, dissemination of experiences in implementing educational programs, evaluation, and accreditation of programs, and finally certification of users in BMHI knowledge and skills. A more detailed reference to the objectives can be found below:

- to disseminate and exchange information on Biomedical and Health Informatics (BMHI) programs and courses.

- to exchange experiences of how BMHI is taught and to improve the implementation

- to establish a database on programs and courses on BMHI education 


\section{EFMI WG EDU}

(continued)
- to produce international recommendations on BMHI education

- to support BMHI courses and exchange of students and teachers within the EFMI countries.

- to foster the accreditation process of BMHI programs in Europe.

- to explore the process of certification of knowledge and skills of users in BMHI

- to investigate the possibility of establishing summer courses organized by the WG EDU

\section{Relevant Activities 2013:}

- A panel discussion was accepted and organized during Medinfo 2013 in Copenhagen for the accreditation process. In the panel besides the chair and co-chair of the WG representatives of AMIA and IMIA joined exchanging experiences and presenting intended activities in accreditation. It was attended my more than a hundred participants.

- A paper prepared by the chair and co-chair was presented as oral presentation at Medinfo 2013 in Copenhagen regarding the accreditation process. It was well accepted.

- During the joint Board meetings of IMIA and EFMI the issue of representation of EFMI in the accreditation process of academic programs was raised and it was agreed that EFMI will be presented in the accreditation committee and EFMI will be mentioned in the accreditation certificate whenever an accreditation is taking place in an EFMI country.

- The activities of the WG EDU and important outcomes will be cited in the new website of the WG EDU.

- A number of educational related papers were presented during the International Conference in Informatics,

- Management and Technology in Healthcare in Athens on July 2013.

\section{Activities Planned for 2014:}

- Enhancing the cooperation between EFMI and IMIA in the accreditation process

- Providing an operational website for the WG EDU

- Pending the final program approval, participating in the Ministerial Conference in eHealth organized by the

- Ministry of Health in Athens on May 2014.

- Organizing a workshop/panel of the WG EDU in MIE 2014 in Istanbul

- Investigating the logistics in supporting a summer course in BMHI

\section{Relevant Publications 2013:}

- Hasman A, Mantas J. IMIA Accreditation of Health Informatics Programs. Healthc Inform Res. 2013 Sep;19(3):154-61. doi: 10.4258/hir.2013.19.3.154. Epub 2013 Sep 30

- Mantas J, Hasman A, Shortliffe EH. Assessment of the IMIA educational accreditation process. Stud Health Technol Inform. 2013;192:702-6.

- Zogas S, Lialiou P, Gallos P, Mantas J. The e-learning programs in Greek Universities: a literature review. Stud Health Technol Inform. 2013;190:89-91.

- Lialiou P, Mantas J. Evaluation of health professionals in the use of Internet information retrieval systems in health: a literature review. Stud Health Technol Inform. 2013;190:80-2.

- Friedman C, Hasman A, Holmes J, Mantas J, Saranto K. International Perspectives on Program Accreditation for Professional Education in Informatics. MedInfo 2013: 1241. 


\section{EFMI WG EHR}

Electronic Health Records
Chair:
Bernd Blobel
eHeadth Competence Center
Medical Foculty
University of Regensburg, Germany
E-mail: bernd.blobel@kklinik.uni-egensburg.de
Co-Chair:
Dipak Kalra
Centre for Health Informatics and Multiprofessional Education
(CHIME)
University College London, UK
E-mail: d.kalra@ @chime.udl.ac.uk
hitrp://www.efmi.org

\section{Main Objectives:}

The working group deals with the issue electronic health records in the different levels of development: case level, organisational level, regional level, national level, and international level. The Working Group supports

- Studies on specification, implementation, and promotion of standards for EHR and PHR

- Modeling of EHR architectures and interoperability

- Education on the EHR field

\section{Relevant Activities 2013:}

- Engagement at EFMI STC 2013 "Data and Knowledge for Medical Decision Support" in Prague, Czech Republic, in cooperation with the EFMI Working Groups "Personal Portable Devices (PPD)" and "Security, Safety and Ethics (SSE)"

- Active involvement in the preparation of pHealth 2013 in Tallinn, Estonia, in cooperation with the EFMI Working Groups "Personal Portable Devices (PPD)" and "Security, Safety and Ethics (SSE)" as well as realization of a pre-conference workshop dedicated to "Reuse and Secondary Use of Health Data - Interoperability, Privacy and Security Challenges".

\section{Activities Planned for 2014:}

- Dipak Kalra takes the lead of the Working Group

- Active involvement in the preparation of pHealth 2014 in Vienna, Austria, in cooperation with the EFMI Working Groups "Personal Portable Devices (PPD)" and "Security, Safety and Ethics (SSE)"

- Preparation of a Workshop at MIE 2014 in Istanbul, Turkey.

\section{Relevant Publications 2013:}

- Blobel B, Goossen W, Brochhausen M (2013) Clinical modeling - A critical analysis. Int. J. Med. Inform. (2013), http://dx.doi.org/10.1016/j.ijmedinf.2013.09.003

- Blobel B (2013) Translational Medicine Meets New Technologies for Enabling Personalized Care. Stud. Health Technol. Inform. 2013; 189: 8-23.

- González C, López DM and Blobel B (2013) Case-Based Reasoning in Intelligent Health Decision Support Systems. Stud. Health Technol. Inform. 2013; 189: 44-49.

- Blobel B (2013) Knowledge Representation and Management Enabling Intelligent Interoperability - Principles and Standards. Stud. Health Technol. Inform. 2013; 186: 3-21.

- Vida M, Stoicu-Tivadar L, Blobel B and Bernad E (2013) Interoperability Evaluation Case Study: An Obstetrics-Gynecology Department and Related Information Systems. Stud. Health Technol. Inform. 2013; 186: 177-181.

- Blobel B, Pharow P, Parv L (Edrs.): pHealth 2013. IOS Press, Amsterdam, Berlin, Oxford, Tokyo, Washington 2013. 


\section{EFMI WG EVAL}

Assessment of Health Information
Systems
Chair:
Elske Ammenwerth
UMIT - University for Health Sciences, Medical Informatics
and Technology
Hall in Tyrol, Austria
E-mail: elske.ammenwerth@umit.at
Co-Chairs:
Pirkko Nykanen
School of Information Sciences
Tampere University, Finland
E-mail: pirkko.nykanen@uta.fi
Jytte Brender
Dept. of Health Science and Technology
Aalborg University, Denmark
E-mail: iytte@brender.dk
hittp://iig.umit.at/efmi//

\section{Main Objectives:}

Information and communications technologies (ICTs) are being used increasingly in health care. It is evident that the use of modern ICT offers tremendous opportunities to reduce clinical errors, to support health care professionals, and to increase the efficiency of care. However, there are also hazards associated with such technologies. Therefore, rigorous, generalizable evaluations of ICT applications in health care are absolutely necessary. Therefore, the aims of the working group are: - to foster discussion between experts from informatics, medical informatics, economics, health care, health services research, clinical epidemiology, biometry, psychology, sociology, ethnography, organizational development, operations research and other evaluation fields, on a European level, and to encourage exchange on methodological issues between researchers from different traditions;

- to offer an opportunity to share knowledge with the aim of obtaining profitable cross-fertilization among different fields of expertise and especially between quantitative and qualitative research;

- to promote a combined research agenda to develop frameworks and toolkits for information systems evaluation, offering guidelines for an adequate combination of evaluation methods and tools;

- to discuss and clarify the networking needs for long-term evaluation research in medical informatics, and to promote combined research proposals at a European level

\section{Relevant Activities 2013:}

- The WG organized a workshop with around 40 participants during Medinfo 2013 in Copenhagen: "Evaluation and Evidence: Applying guidelines for health IT evaluation in developed and developing countries" (for details, see http://iig.umit.at/efmi)

- The WG organized a joint Business Meeting with the sister WGs on Health IT Evaluation of AMIA (American Medical Informatics Association) and of IMIA (International Medical Informatics Association) at Medinfo 2013 in Copenhagen. Future joint activities were discussed and planned.

- An elaboration paper on STARE-HI has been published and is available open access (for details, see publication list).

- A special issue dedicated to the evaluation of CDSS in the journal "Artificial Intelligence in Medicine" was coordinated and edited by the Working Group. The issue contains six selected papers on CDSS evaluation methodology and practice (for details, see publication list).

- In the IMIA Yearbook 2013, an overview paper on the work of the WG in the last decade was published. It summarizes the achievements of the WG since its "Declaration of Innsbruck" published in 2003 (for details, see publication list).

- The bibliography on health IT Evaluation was updated and is now available at http://iig. umit.at/efmi/bibliography.htm. The list contains journal papers and books considered as milestone publications.

- The web-based Health IT Evaluation Inventory was updated. It now comprises around 1.800 abstracts of evaluation papers in health informatics that can be retrieved. It also allows researchers from all over the world to submit papers for inclusions. The Health Evaluation Inventory is available for free at http://evaldb.umit.at.

\section{Activities Planned for 2014:}

- Strengthening of the links to the sister WGs of AMIA and IMIA by joint activities

- Extending the links to the WHO Global eHealth Evaluation Collaboration

- Organization of an AMIA Webinar on the STARE-HI explanation and elaboration paper in February 2014

- Organization of a workshop on health IT evaluation education at MIE 2014

- Further update of the health IT Evaluation Inventory.

\section{Relevant Publication 2013:}

- Ammenwerth E, de Keizer N, Rigby MJ, Nykänen P, Talmon J, Brender J. Promoting Evidence-Based Health Informatics - A Decade of Effort. Poster at Evidence Live 2013, 25. - 26.3.2013, Oxford, UK. 


\section{EFMI WG EVAL}

(continued)

\section{EFMI WG HIIC}

\section{Health Informatics for Interregional Cooperation}

\author{
Chair: \\ Lacramioara Stoicu-Tivadar \\ University "Politehnica" Timisoara \\ Timisoara, Romania \\ E-mail: lacramioara.stoicu-tivadar@aut.upt.ro \\ http://www.efmi.org
}

- Ammenwerth E, Nykänen P, Rigby M, de Keizer N (eds): Special Issue: Evaluation of Clinical Decision Support Systems. Artif Intell Med 2013; 59(1): 1-54.

- Brender J, Talmon J, de Keizer N, Nykänen P, Rigby M, Ammenwerth E. STARE-HI - Statement on Reporting of Evaluation Studies in Health Informatics Explanation and Elaboration. Appl Clin Inform 2013; 4: 331-58. http://dx.doi.org/10.4338/ACI-2013-04-RA-0024

- Rigby M, Ammenwerth E, Beuscart-Zephir MC, Brender J, Hyppönen H, Melia S, Nykänen P, Talmon J, de Keizer N. Evidence Based Health Informatics: 10 Years of Efforts to Promote the Principle. IMIA Yearbook of Medical Informatics 2013; 34-46.

\section{Main Objectives:}

- To promote exchange of information and experiences between actors in different regions in Europe.

- To investigate the needs, opportunities and obstacles for e-health and to review and select from different education options for developing regions.

- To disseminate European and world-wide results and experiences across regions and between professionals

- To facilitate access to European groups and their facilities and outcomes by students and health professionals from developing regions

- To disseminate European and world-wide results and experiences across developing regions and professionals

\section{Relevant Activities 2013:}

- Participation in STC2013, Prague, Czech Republic, workshop Sharing Knowledge and Tools for Decision Support in Biomedicine and Health Care

- Advocating at national level the e-health activities related to cross border EC directive regarding healthcare mobility starting October 2013.

- Participation in Medinfo2013, Copenhagen, Denmark

\section{Activities Planned for 2014:}

- Support and participation in EFMI STC2014, Budapest, Hungary

- Participation in EFMI MIE2014, Istanbul, Turkey

- Resuming close cross border cooperation with neighbors, Hungary (Szeged) and Serbia (Vrsac) in medical informatics education and e-health projects

\section{Relevant Publications 2013:}

- Vida, M., Stoicu-Tivadar L., Blobel B., Bernad E. Interoperability Evaluation Case Study: An Obstetrics-Gynecology Department and Related Information Systems, Studies in Health Technology and Informatics, Vol. 186, Data and Knowledge for Medical Decision Support, Proceedings of EFMI-STC 2013, Prague, Cech Republic, pp177-182.

- Vida, M., Stoicu-Tivadar, L., Marcovici, A., ICT solution for assisted diagnosis based on monitoring in cardiology departments (Best paper award), IEEE International Conference on e-Health and Bioengineering, EHB 2013, Iasi, Romania, pp. 1-4.

- Lupse, O.S., Stoicu-Tivadar, L., Golie, C., Assisted prescription based on successful treatments, IEEE International Conference on e-Health and Bioengineering, EHB 2013, Iasi, Romania.

- Crisan-Vida, M., Stoicu-Tivadar, L., Lupse, O., Blobel, B., Bernad E., Models Supporting Development of Complex Information Systems in Healthcare. Case study: an Obstetrics-Gynecology Department, EJBI - Volume 9 (2013), Issue 1, en18-en23. 


\section{EFMI PG HIME}

Health Information Management Europe
Chair:
Rolf Engelbrecht
USMFChisinau
E-mail: Engelbrecht@EFMI.info
Co-Chair:
Angelika Haendel
President of IFHIMA.DVMD board member
University of Erlangen-Nuremberg
Schwabachanlage 6
Erlangen
Germany
E-mail: angelika.haendel@uk-erlangen.de
Co-Chair:
Lorraine Nicholson
E-mail: I.nicholson@zen.co.uk
http://www.efmi.org
http://www.linkedin.com/groups/EFMI-HIME-Health-Informati-
on-Management-4550722/about

\section{EFMI WG IDeS}

Information and Decision Support in Biomedicine and Health Care

Chair:

Zdenko Sonicki

Andrija Stampar School of Public Health

School of Medicine

University of Zagreb, Croatia

E-mail: zdenko.sonicki@snz.hr

\section{Co-Chair:}

Kristina Fišter

Andrija Stampar School of Public Health

School of Medicine

University of Zagreb, Croatia

E-mail: kristina.fister@snz.hr

\section{Main Objectives:}

The group operates as a "think-tank" drawing together leading-edge expertise not only from across the medical documentation and medical informatics spectrum but also from other professions with relevant generic input to focus on selected topic areas in support of clinical and healthcare research and routine processes.

- To promote exchange of experience in development, implementation, education, and use of health record systems

- To promote exchange of standards in close co-operation with SDOs (standard development organizations) and institutions working in the field on national and European level.

- To investigate the needs, opportunities and obstacles for health information management.

- To disseminate results and experiences across EFMI members

- To facilitate access to European educational facilities and EFMI members

Activities in general:

- Supporting activities of EFMI, its members (resp. their national societies) and IFHIMA-Europe, especially MIE and STC conferences.

- Organizing workshops on national and European level

- Initiation of a Forum using Internet and other publication media.

- Making educational and promotional material available

- Preparation of IFHIMA (International Federation of HIM associations) conferences

Relevant Actiities 2013:

- Further extension of the LinkedIn group EFMI-HIME. Number of members above 400 25 topics for discussion and announcements in 2013

- Seminar HIME at STC2013 in Prague, 17 April at House of Physicians 8 international presentations http://stc2013.org/assets/files/STC2013\%20Seminar\%20HIM\%20final.pdf

- Participation with presentation in IFHIMA 2013 conference in Montreal / Canada

Activities Planned for 2014:

- Organization of discussions and promotions on the LinkedIn group EFMI-HIME

- Seminar HIME at STC2014 in Budapest

- Workshop on "Capacity Planning" at Schliersee-Konferenz 28 January

- Concept for "Capacity Planning" modules and development

- Workgroup meeting during MIE2014

- Presentation at WCIT 2014, Guadalajara / Mexico

\section{Main Objectives}

Decision support systems (DSS) in biomedicine and health care, in the form of various applications, guidelines or reminders, is applied more often to assist the decision making processes. The complexity of decision-making procedures in these areas caused the development of various decision support systems in order to provide help to the decision makers. DSS are using existing knowledge and evidence, helping the decision maker to make appropriate decision for the specific situation. The quality and comprehensiveness of existing evidence and knowledge that are used in such systems, influence in deriving appropriate decisions, and indirectly affects decision maker's behavior. DSS needs to be analyzed, systematized, and validated before adopting them for routine use because of its influence on decisions and decision makers.

- Analysis of currently available Decision Support Systems in biomedicine and health care, especially in the European environment

- Classification of existing Decision Support Systems

- Definition of the recommendations set for successful evaluation and implementation of the Decision Support Systems

\section{Relevant Activities 2013:}

- Proposal of the new EFMI WG focused on DSS issues in biomedicine and health care was accepted at the EFMI STC Conference in Prague, April 17th-19th 2013. 


\section{EFMI WG IDeS}

(continued)

http://www.efmi.org

\section{EFMI WG LIFOSS}

Libre/Free and Open Source Software in Health Informatics

Chair:

Thomas Karopka

BioCon Valley GmbH

Germany

E-mail: tk@bcv.org

http://www.efmi.org
- Presentation of the new EFMI WG at the CSMI Annual Assembly in Zagreb, Croatia, September 19th 2013.

- Special Session on Decision Support Systems in Health Care at the Medical Informatics 2013, 11th Symposium of CSMI, Dubrovnik, Croatia, 7th - 9th November 2013. (http:// www.hdmi.hr/index.php/dogadanja-i-skupovi/61-medical-informatics-2013)

Activites Planned for 2014:

- Working group day at the MIE conference in Istanbul

- Working group meeting in Croatia

Relevant Publications 2013:

- Sonicki Z, Fišter K, Kern J, Vuletić S. New EFMI Working Group "Information and Decision Support in Biomedicine and Health Care". Med.Inform. 2013;11:41-42.

- Deželić G. The beginnings of medical informatics research in the field of medical decision-making in Croatia. Med.Inform. 2013;11:43-44.

- Kern J. Decision Support System - What it is and why we need it? Med.Inform. 2013;11:45-46.

- Somek M, Hercigonja-Szekeres M. Predikcija bolničkih infekcija dubinskom analizom podataka. Med.Inform. 2013;11:47-52. (in Croatian)

- Dobša J, Daraboš N. Usage of decision tree for determination of nail position in tibial intramedullary nailing. Med.Inform. 2013;11:53-54.

- Meštrović T, Sonicki Z, Petrunić M, Premužić-Meštrović I. Operative mortality prediction models in ruptured abdominal aortic aneurysms. Med.Inform. 2013;11:55-56.

- Šimurina T, Sonicki Z, Kern J, Ivanković D. Predictive model of vomiting following gynecological surgery under general anesthesia. Med.Inform. 2013;11:57-58.

- Šlić K, Kramarić-Ratković K, Antolović Z. Applying Evidential Reasoning Approach in biomedicine - example of the APGAR score. Med.Inform. 2013;11:59-60.

\section{Main Objectives:}

- to help replicate the success of free/libre and open source projects in the health informatics domain, in particular those within education, research, clinical practice and administration

- to build a repository of knowledge about free/libre and open source developments of relevance to the health informatics domain

- to develop an Open Source Market Place

- to explore the implications of digital rights management, digital signatures, copyright and intellectual property issues

- to liaise with other organizations and groups with related or similar objectives

Relevant Activities 2013:

- Support and participation in IWEEE 2013, Las Palmas, Gran Canaria

- Co-organization of FLOSS Village at Med-e-Tel 2013, April 2013, Luxemburg

- Co-organization of "Care for the World"-Workshop at MEDINFO2013, Copenhagen, Denmark

- Maintenance of the MedFLOSS.org database

- Participation in 14es Rencontres Mondiales du Logiciel Libre, July 2013, Bruxelles

- Representatives of the NLU WG are actively participating in research project accepted and under preparation, including Innovative Medicine Initiative's projects

Activities Planned for 2014:

- Further promotion of FLOSS in health care in Europe as well as on a global level

- Maintenance of the MedFLOSS.org database

- Further Collaboration with other working groups (e.g. AMIA OS WG, IMIA OS WG)

- Review of state of FLOSS in health care on a global level

- Contributions to MIE 2014 and EFMI STC 2014

- Work on contribution for MEDINFO 2015

Relevant Publications 2013:

- Schmuhl H., Heinze O. Bergh B. Use of Open Source Software in Health Care Delivery - Results of a Qualitative Field Study. Contribution of the EFMI LIFOSS Working Group. Yearb Med Inform 2013;8(1):107-13. Retrieved from http://www.ncbi.nlm.nih.gov/pubmed/23974556 


\section{EFMI WG NURSIE}

\author{
Nursing Informatics in Europe \\ Chair: \\ Patrick Weber \\ Nice Computing \\ Ch. de Maillefer 37 \\ CH-1052 Le Mont-sur-Lausanne \\ Switzerland \\ E-mail: patrick.weber@nicecomputing.ch \\ Co-Chair: \\ Thomas Bükle \\ Lehrstuhl für Medizinische Informatik \\ Universitöt Erlangen \\ Krankenhausstraße 12 \\ D-91054 Erlangen, Germany \\ E-mail: thomas.buerkle@imi.med.uni-erlangen.de \\ http://www.nicecomputing.ch/nieurope
}

\section{EFMI WG PCI}

\section{Primary Care Informatics}

Chair:

Simon de Lusignan

Clinical Informatics and Health Outcomes Research Group

Department of Health Care Management and Policy

University of Surrey, Guildford, GU2 7XH, UK

E-mail: s.lusignan@surrey.oc.uk

htrp://www.clininf.eu/about/efmipciwg.html

\section{Main Objectives:}

- To support nurses and nursing organizations in the European countries with information and contacts in the field of informatics.

- To offer nurses opportunities to build contact networks within the informatics field. This could be accomplished by arranging sessions, workshops and tutorials in connection with the Medical Informatics European (MIE) conferences or by arranging separate meetings.

- To support the education of nurses with respect to informatics and computing.

- To support research and developmental work in the field and promote publishing of achieved results.

\section{Relevant Activities 2013:}

- We were active in Acendio meeting in Dublin and we are preparing together with the Swiss Nursing informatics group the Acendio conference in 2015 in Bern Switzerland.

- We also are hardly working on the IMIA NI conference NI2016 in Geneva.

- Croatian Medical Informatics Association invited November 2013 representatives from Belgium (W. Sermeus and T Gypen) and from Switzerland (P Weber) for their annual conference.

- The European Nursing Group has to be reorganized. New President should be nominated and the Countries representatives should be more active.

- We are waiting for EFMI new website to update the Nursing activities

\section{Main Objectives}

The group aims to be a focus for people to from a primary health care background, or conducting research into primary care to come to EFMI conferences. We aim to put on events, generally workshops at EFMI meetings and use the outputs from these to create a submission to the following years IMIA Yearbook for Medical Informatics. We work in close collaboration with national and the IMIA primary care working groups.

- The aim of the group is to promote and develop primary care informatics as a specialism within health informatics [1].

- The group aims to put on workshops, and where feasible visits to primary health care facilities, at EFMI conferences.

- Increase the peer review primary health care informatics literature.

- Our three current themes are: (1) How to model research studies based on routinely collected data [2]; (2) Ontologically rich approached to case finding in routine data [3]; (3) Methods for the direct observation of the use of technology in the clinical consultation [4]..

\section{Relevant Activities 2013:}

- MEDINFO 2013 Denmark: We held a workshop 22nd August to explore the role Primary Care Informatics in underpinning patient safety and clinical governance; exploring how to develop an international perspective to this theme [5].

- EFMI STC 2013 Prague: We co-organised a workshop: Using Information to Improve the Quality of Care in Type 2 Diabetes in Primary Care, which took place April 16th 2013, 15.00 - 18.00 in the Great Hall of Facultz of Medicine of Charels Universit in Prague [6]; co-chaired by Profs Simon de Luisignan and Št pán Sva ina. There have been collaborative publications from this workshop [7].

- Yearbook of Medical Informatics 2013: The WG developed a paper developed from our workshop on use of ontologies and sematic integration to support chronic disease management [8].

\section{Activities Planned for 2014:}

- EFMI STC Prague 2013: Workshop on detecting the miscoding, misclassification of diabetes.

- IMIA MEDINFO Conference 2013: We plan to run a workshop in collaboration with the IMIA PCI WG. 


\section{EFMI WG PCI}

(continued)

\section{EFMI WG PPD}

\section{Personal Portable Devices}

\section{Chair:}

Lenka Lhotska

Department of Cybernetics

Faculty of Electrical Engineering

Czech Technical University

Prague, Czech Republic

E-mail:Ihotska@labe.felk.cvut.cz

\section{Co-Chair:}

Paul Cheshire

United Kingdom

E-mail: efmi_ppd@yahoo.co.uk

\section{Co-Chair:}

Peter Pharow

Fraunhofer IDMT IIImenau, Germany

E-mail: peter.pharow@web.de

http://www.EFMl.org

\section{Relevant Publications 2013:}

1. de Lusignan S. What is primary care informatics? J Am Med Inform Assoc. 2003;10(4):304-9

2. de Lusignan S, Pearce C, Kumarapeli P, Stavropoulou C, Kushniruk A, Sheikh A, Shachak A, Mendis K. Reporting Observational Studies of the Use of Information Technology in the Clinical Consultation. A Position Statement from the IMIA Primary Health Care Informatics Working Group (IMIA PCI WG). Yearb Med Inform. 2011;6(1):39-47.

3. Liaw ST, Rahimi A, Ray P, Taggart J, Dennis S, de Lusignan S, Jalaludin B, Yeo AE, Talaei-Khoei A. Towards an ontology for data quality in integrated chronic disease management: a realist review of the literature. Int J Med Inform. 2013;82(1):10-24.

4. de Lusignan S, Liaw ST, Krause P, Curcin V, Vicente MT, Michalakidis G, Agreus L, Leysen P, Shaw N, Mendis K. Key Concepts to Assess the Readiness of Data for International Research: Data Quality, Lineage and Provenance, Extraction and Processing Errors, Traceability, and Curation. Contribution of the IMIA Primary Health Care Informatics Working Group. Yearb Med Inform. 2011;6(1):112-20.

5. Pearce CM, de Lusignan S, Phillips C, Hall S, Travaglia J. The computerized medical record as a tool for clinical governance in Australian primary care. JMIR Res Protoc. 2013 Aug 12;2(2):e26. doi: 10.2196/ijmr.2700.

6. EFMI PCI WG Workshop EFMI STC2013 Prague. URL: http://stc2013.org/assets/files/ WS3_UsingInformation_Diabetes.pdf

7. Seidu S, Davies MJ, Mostafa S, de Lusignan S, Khunti K. Prevalence and characteristics in coding, classification and diagnosis of diabetes in primary care. Postgrad Med J. 2014 Jan;90(1059):13-7.

8. Liyanage H, Liaw ST, Kuziemsky C, Terry AL, Jones S, Soler JK, de Lusignan S. The Evidence-base for Using Ontologies and Semantic Integration Methodologies to Support Integrated Chronic Disease Management in Primary and Ambulatory Care: Realist Review. Contribution of the IMIA Primary Health Care Informatics WG. Yearb Med Inform. 2013;8(1):147-54.

Informatics in Primary Care remains the journal of choice for the working group; http:/hijournal.bcs.org/ SdeL is the Editor with other key members of the working group involved with the journal. The journal is now free-full-text online and also free to publish; due to the support of the British Computer Society (BCS) Health. Submission is now via an online submission system.

\section{Main Objectives:}

EFMI Working Group (WG) Personal Portable Devices (PPD) aims at being a European competence center to watch ongoing activities and to provide knowledge to policy makers and architect designers involved in the deployment of projects related to personalized, portable devices (PPD) such as cards, tokens, wearable and portable devices, sensors and actuators, and similar technologies including advanced network infrastructures mainly in the domain of healthcare and welfare. WG PPD links its activities to the domain of Ambient Assisted Living by liaising with the IMIA WG on Smart Homes and AAL.

Furthermore, WG PPD representatives are actively involved in standardization activities in various fields and domains including security, safety, management, ethics, medical devices, and sensor networks. Members of WG PPD act as a kind of ambassador to additional standards developing organizations in various other domains, where aspects of personal portable (mobile) devices are addressed.

Moreover, WG PPD actively supports the organization of meetings of various kinds to disseminate the WG achievements, and to exchange knowledge and information about any topic linked to the interest of the WG PPD members. The main topics the WG PPD is focused on are:

- Personal(ized) Portable Devices, sensors and actuators as well as the underlying networks enable personal and even personalized health service provision going far beyond traditional care procedures. It includes wellness aspects, lifestyle aspects, and safety aspects. Applications from other domains stimulate the respective paradigm shift towards personalized services (addressing citizens rather than patients) also in the healthcare and welfare domain.

- The paradigm shift from health cards to personalized devices and sensor networks for providing personal health services addresses various technical, medical, organizational, 


\section{EFMI WG PPD}

(continued) legal, and standardization aspects of portable devices (EFMI WG PPD) and related work on sensor networks (ISO/IEC JTC1 SGSN). What EFMI WG PPD is aiming at from a technological viewpoint, are aspects of the present and the near future of personal health service provision supported by devices of any technology, any kind and any size either directly applied to the human body, or placed even inside the body.

\section{Relevant Activities 2013:}

- The WG organized a workshop with around 20 participants during EFMI STC 2013, April 16, 2013 in Prague, Czech Republic. The title of the workshop: "Decision Support and Decision Making Enabled by Personal Portable Devices" (see program at http://stc2013. org/assets/files/WS2_PPD.pdf)

- Active participation in pHealth 2013 conference in Tallin, Estonia - Peter Pharow, SPC Chair (see program at http://phealth2013.eu/uploads/keepitsimple/pHealth\%202013\%20 PROGRAM_19.06.pdf), presentation of papers (for details, see publication list)

- Organization of mini-symposium Privacy and Network Security at the ICHI 2013 (IFMBE International Conference on Health Informatics), Vilamoura, Portugal

- Special session "Assistive Technology in Healthcare" at the Medtel conference in Prague, Czech Republic (see program at http://www.action-m.com/medtel2013/odborny-program.php)

- Preparation of a WG meeting in Munich, Germany (February 2014)

\section{Activities Planned for 2014:}

- WG meeting in Munich, Germany, February 27-28, 2014

- Strengthening of the links to relevant societies and their working groups

- Submission of a Joint Workshop proposal to MIE 2014 in cooperation with the EFMI WGs SSE and EHR

- Active participation in pHealth 2014, Vienna, Austria

\section{Relevant Publications 2013:}

- EFMI STC 2013 Workshop Decision Support and Decision Making Enabled by Personal Portable Devices, Chairs: Lenka Lhotská and Peter Pharow; presentations:

- Decision Support and Decision Making Enabled by Personal Portable Device (Lenka Lhotská, Paul Cheshire, Peter Pharow)

- Human Factors in Design and Development of Personal Portable Devices (Lenka Lhotská, Peter Pharow, Paul Cheshire)

- Possibilities of Personal Healtch Status Monitoring (Jan Havlík, Jan Dvořák, Jakub Parák, Matouš Pokorný, Lenka Lhotská, Petr Panýrek)

- Air Quality Early Warning To Prevent Breathing Difficulty (Jiri Havlik)

- AsTeRICS - The Assistive Technology Rapid Integration \& Construction Set (Alice Bednárová, Tomáš Drajsajtl, Petr Struk)

- Cheshire, P. - Lhotská, L. - Pharow, P.: Virtual Physiological Human and its Role for Advanced pHealth Service Provision. In Proceedings of the 10th International Conference on Wearable Micro and Nano Technologies for Personalized Health. Amsterdam: IOS Press, 2013, p. 33-37. ISSN 0926-9630.ISBN 978-1-61499-267-7.

- Pharow, P. - Lhotská, L. - Cheshire, P.: Personal Portable Devices as Enablers for Advanced pHealth Decision Support and Decision Making Services. In Proceedings of the 10th International Conference on Wearable Micro and Nano Technologies for Personalized Health. Amsterdam: IOS Press, 2013, p. 27-32. ISSN 0926-9630.ISBN 978-1-61499-267-7.

- Medtel 2013 presentations:

- Lenka Lhotská, Olga Štěpánková, Czech Technical University in Prague: Personal Portable Devices - Theory and Practice

- Peter Pharow, Fraunhofer IDMT (Germany): Gamification - Using a PPD and its Opportunities for $\{e ; m ; p\}$ Health Applications

- Jiří Havlík, IMA s.r.o.: Nanoelectronic for Mobile AAL Systems: Air Quality Monitoring

- Asbjørn Hovstø, ITS NorwayPublication 5: Sensors, Actuators, and Sensor Networks Enabling and Supporting eHealth 


\section{EFMI WG SSE}

\author{
Security, Safety and Ethics \\ Chair: \\ Bernd Blobel \\ eHealth Competence Center \\ Medical Foculty \\ University of Regensburg \\ Germany \\ E-mail: bernd.blobel@klinik.uni-regensburg.de \\ Co-Chair: \\ Pekka Ruotsalainen \\ School of Information Science \\ Centre of Information and Systems \\ University of Tampere, Finland \\ E-mail: pekka.ruotsalainen@uta.fi \\ htrp://www.efmi.org
}

\section{Main Objectives:}

Speeding up the use of ICT for health care increases the challenge for trustworthiness, security and safety of solutions and infrastructure deployed. The WG aims to promote development, education and training on the field of security and privacy in health care. Close collaboration with other EFMI-WGs and beyond as well as with IMIA WG4 as for securing their ICT solutions for health care.

\section{Relevant Activities 2013:}

- Engagement at EFMI STC 2013 "Data and Knowledge for Medical Decision Support" in Prague, Czech Republic, in cooperation with the EFMI Working Groups "Electronic Health Records (EHR)" and "Personal Portable Devices (PPD)".

- Active involvement in the preparation of pHealth 2013 in Tallinn, Estonia, in cooperation with the EFMI Working Groups "Electronic Health Records (EHR)" and "Personal Portable Devices (PPD)" as well as realization of a pre-conference workshop dedicated to "Reuse and Secondary Use of Health Data - Interoperability, Privacy and Security Challenges".

- The WG-Chair provided an invited talk to the COMSATS-WHO Seminar, 22 October 2013, Islamabad, Pakistan, on "Intelligent Security and Privacy Solutions for Personalized eHealth and Telemedicine".

\section{Activities Planned for 2014:}

- Pekka Ruotsalainen takes the lead of the Working Group

- Active involvement in the preparation of pHealth 2014 in Vienna, Austria, in cooperation with the EFMI Working Groups "Electronic Health Records (EHR)" and "Personal Portable Devices (PPD)"

- Preparation of a Joint Workshop at MIE 2014 in Istanbul, Turkey, in cooperation with IMIA Working Group "Security in Health Information Systems" under the work title "Policy-driven management of personal health information for improved care".

\section{Relevant Publications 2013:}

- Ruotsalainen PS, Blobel Bernd, Seppälä A, Nykänen P (2013) Trust Information-Based Privacy Architecture for Ubiquitous Health. JMIR Mhealth Uhealth 2013; 1(2):e23, URL: http://mhealth.jmir.org/2013/2/e23/

- Nykänen P, Seppälä A, Ruotsalainen P, Blobel B (2013) Feasibility analysis of the privacy attributes of the personal wellness information model. Stud. Health Technol. Inform. 2013; 192: 219-223.

- Blobel Bernd (2013) Translational Medicine Meets New Technologies for Enabling Personalized Care. Stud. Health Technol. Inform. 2013; 189: 8-23.

- Blobel B, Pharow P, Parv L (Edrs.): pHealth 2013. IOS Press, Amsterdam, Berlin, Oxford, Tokyo, Washington 2013. 